\title{
Active Participation and Well-Being Among the Elderly in Belgium and the USA: A Cross-National Time-Use Perspective
}

\author{
Theun Pieter van Tienoven ${ }^{1,3}$ (D) $\cdot$ Lyn Craig $^{2}$ (D) $\cdot$ Ignace Glorieux $^{3} \cdot$ Joeri Minnen $^{3}$ (D)
}

Accepted: 12 May 2020

(c) Springer Nature B.V. 2020

\begin{abstract}
Active participation of the elderly is a recognized response to address the societal and individual challenges of rising life expectancy such as releasing the pressure of age-related public spending, reducing social isolation and improving well-being. How much time older people devote to active participation and whether their time allocation is associated with well-being remains under-investigated. Using time-use data from Belgium $(n=1384)$ and the USA ( $n=2133)$, we investigate the time older people (65-80 years) spent on active participation and examine how this relates to their life satisfaction as an indicator of wellbeing. The countries vary in the amount of time spent on paid employment and volunteering, but not on informal help. Belgian older people spend much less time on paid employment than their American counterparts. This implies more are available to volunteer and provide informal help. Yet participation rates in these activities are higher in the USA. Multivariate analyses show that associations between active participation and life satisfaction vary between both countries and within both countries by gender and age. Overall, positive associations between paid work and volunteering and life satisfaction suggest that governments would do well to mobilize elderly into active participation, especially in Belgium. Negative associations between informal help and life satisfaction suggest governments should provide greater support for informal carers.
\end{abstract}

Keywords Well-being $\cdot$ Time-use $\cdot$ Elderly $\cdot$ Life satisfaction $\cdot$ Active participation

\section{Introduction}

Over the last decade, life expectancy after the age of 65 has been hovering around 20 to 22 years for women and 18 to 20 years for men in the Western world (OECD 2018). This longevity provides substantial challenges both for societies and individuals. Socially,

Theun Pieter van Tienoven

t.vantienoven@unsw.edu.au

1 Social Policy Research Centre, University of New South Wales, Sydney, Australia

2 School of Social and Political Sciences, University of Melbourne, Melbourne, Australia

3 Research Group TOR, Vrije Universiteit Brussel, Brussels, Belgium 
population aging puts pressure on age-related public spending such as pensions, health care and long-term care (European Commission 2018). At the individual level, loss of social roles at later age, for example due to retirement or after children leave home, has been associated with reduced well-being (Ten Bruggencate et al. 2018). So some argue that retirement as a process of social exclusion is no longer desirable and should be replaced by the idea of 'active aging' (Zaidi et al. 2017).

In response to the above, both policy makers and scholars stress the importance of extending working lives, and of older people actively participating beyond the sphere of formal employment (European Commission 2018; López-López and Sánchez 2020). Paid activities and unpaid productive activities are two of the four domains of active and healthy ageing (the other two are independent, healthy and secure living and the capability to age actively) (Zaidi et al. 2017). Most scholars agree productive activities include paid and unpaid work, informal care or helping, and (formal) volunteering (Serrat et al. 2020; Adjei and Brand 2018).

At the societal level, employment at later age might counter imbalances in the labor force and enhance the sustainability of pension systems (European Commission 2018). Grandparents' informal help might address the childcare needs of working parents (Craig and Jenkins 2016b). Older people's volunteering might strengthen the voluntary sector through creating networks and promoting cooperation which, in turn, increases social cohesion in welfare states (Putnam 2000; Musick and Wilson 2007). At the individual level, active participation has a plethora of health benefits. Physical, cognitive and social activities at later ages positively affect physical and emotional health (Matz-Costa et al. 2016), reduce isolation and loneliness (World Health Organization 2015), add to a positive sense of well-being (Halaweh et al. 2018), and increase the likelihood of using preventive health care services (Kim and Konrath 2016).

Substantial research exists on active participation of older people in socioeconomic activity and its relation to health and well-being based on longitudinal survey data from studies such as English Longitudinal Study of Aging (ELSA), the Survey of Health, Aging, and Retirement in Europe (SHARE) and the Americans' Changing Life Study (ACL). Yet most research is based on binary measures (e.g. Have you participated over the last month?) or categorical measure (e.g. Last month how often did you participate?). Relatively little is known about daily time spent by older people in active participation (see Gauthier and Smeeding 2003 for a brief overview), let alone how this relates to older people's well-being, or how it compares to the amount of time spent on active participation of the working population. The aim of this paper is to take a first step in closing this gap in existing knowledge. It will use time-use data from the American Time Use Survey (ATUS) and the Belgian Time Use Survey (BTUS), both of which are nationally representative. Time-use surveys combine time-diaries that provide direct information about activity in the private sphere, where most of the participatory activity of the ageing population is situated (e.g. childcare for grandchildren, volunteering, organizational work) with questionnaires that measure factors such as well-being, general health and subjective time pressure (Robinson and Godbey 2010). In this study we use a general measure of life satisfaction as an indicator of well-being from the survey questionnaire that came with the time-diary. A cross-national comparisons allow us to link institutional context to how people live on a daily basis (Arts and Gelissen 2010).

In what follows we give a brief overview of the individual and institutional determinants of active participation, how active participation relates to well-being, and what is currently known about older people's time-use patterns. We then introduce the American and Belgian time-use survey data, and present results on the amount of daily time older 
people spend on active participation and on the relationship between this time investment and their well-being. The final sections discuss the findings and conclude.

\section{Background}

\subsection{Active Participation and Individual Characteristics}

With regard to the individual characteristics relating to participation in productive activities, two major approaches can be distinguished. One approach centers around the relationship between various productive activities, whereas the other centers around the relationship between socio-demographic characteristics and individuals' health status on the one hand and active participation on the other.

Research on the relationship between various productive activities focusses on whether these activities are complementary or competitive (Hank and Stuck 2008). This largely depends on the type of activity (Burr et al. 2007). For the USA, Mutchler et al. (2003) report a negative association between full time employment and volunteering but no association between paid employment and providing informal care. For four Western European countries, Di Gessa and Grundy (2017) report a negative association between paid employment on the one hand and volunteering and informal helping on the other, but a positive association between retirement and these activities. However, they conclude that baseline engagement in volunteering and informal helping was the strongest predictor for continued active participation at later age, suggesting that "older people who are active are likely to stay active" (Di Gessa and Grundy 2017, p. 1031).

The association between informal helping and volunteering is generally reported to be complementary both in Europe (Hank and Stuck 2008) and the USA (Choi et al. 2007). However, looking into more detail, Arpino and Bordone (2017) find that grandmothers' regular provision of childcare has a negative effect on volunteering. On the other hand, Burr et al. (2005) report that older people already engaged in informal care are more likely to volunteer than those not engaged in informal care.

Whether or not older people actively participate also depends on certain demographic characteristics and their health status. In Europe, workforce participation after retirement age is mainly determined by socio-economic status (van Tilburg et al. 2010). Similarly for the USA, Pleau and Shauman (2013) report that income is inversely associated with reemployment after retirement. Two of the few studies that analyze time spent on active participation report no distinctive trends by age (Gauthier and Smeeding 2003; McKenna et al. 2007). In fact, health seems to be more predictive of volunteering than age (Papa et al. 2019; Principi et al. 2016). Gender plays a significant role in providing childcare for grandchildren (Craig and Jenkins 2016b; Horsfall and Dempsey 2015) and for informal care and volunteering in general (Hook 2004), with women more than men engaging in these activities.

\subsection{Time Spent on Active Participation}

As summarized above, much is known about the determinants of older people's active participation. Much less is known about cross-national variations in older people's time in active participation. A few cross-national studies have compared older people's time in paid and unpaid work, leisure and sleep, reporting that gender inequality in time spent on 
housework continues at older ages in all countries studied (Adjei and Brand 2018; Adjei et al. 2017). With regard to age, Gauthier and Smeeding (2003) report that time-use figures for childcare, volunteering, and paid work show no distinctive trends over the age of 45 to 75 + years. Other research explicitly on older people's time-use patterns dates back to 1980 s but often focused on special groups (urban elderly in different living situations in Moss and Lawton 1982; older people in pre- and post-retirement in Zuzanek and Box 1988) and did not examine active participation. Hook (2004), on the other hand, did focus on the time spent on volunteering and providing informal care, recognizing the need to include these time investments in estimates of household labor, but focused on married couples across all ages.

Grandparenting is one form of informal care that has been studied more extensively using time-use surveys. Craig and Jenkins (2016a) for example, report for Australia that grandfathers and grandmothers average 20 and 40 min per day on childcare, respectively. Grandfathers and grandmothers that identify themselves as 'regular carers' spend almost 60 and over 100 min per day on childcare, respectively (Craig and Jenkins 2016b). Despite the above and to the best of our knowledge, it seems that to date, cross-national, population wide research on older people's time-use patterns and how this relates to their well-being remains little explored.

\subsection{Active Participation and Well-Being}

According to the World Health Organization physiological well-being as well as psychological and social well-being are all part of general health (World Health Organization 1948). Based on a review of 99 self-report measures of physical, mental and social wellbeing, Linton et al. (2016) conclude that "many of the multidimensional measures of wellbeing strongly resemble measures of general health. Drawing a distinction between general well-being and general health may be too subtle; however, [subjective well-being] may differ from health in that it inherently targets how individuals think and feel about the quality of their own lives" (p. 13). Commonly, though, self-reported general health serves as a proxy of overall well-being.

The health and well-being benefits of volunteering have been studied extensively (see for overview Jenkinson et al. 2013). Volunteering at later age is helpful for mental wellbeing (Tabassum et al. 2016). At least three factors are linked to the association between active participation and well-being. First, active participation through volunteering and informal care is considered prosocial behavior which positively affects well-being by generating a greater sense of meaning, a self-validating experience, and by promoting positive role identities (Wilson 2000). Second, the physical aspect of engagement in paid work, informal care or volunteering provides important health benefits (Jenkinson et al. 2013). Third, active participation might increase the availability of social support from informal networks such as family and friends (Pilkington et al. 2012; Quirke et al. 2019). However, positive aspects of volunteering and informal care might be annulled or reversed when physical, emotional and time demands become excessive. Craig and Jenkins (2016b) report that informal help such as grandparenting negatively affects grandparents' well-being if childcare becomes too regular and demanding. McMunn et al. (2009) find that informal carers who did not feel appreciated report worse life satisfaction scores than non-carers.

The health and well-being benefits of paid employment and unpaid work at later age have been studied less extensively. It has long been suggested that the unequal division of labor is associated with adverse health outcomes in women (Bird 1999), but recent studies 
found that the time allocated to housework activities positively relates to self-reported general health among older men and women (Adjei and Brand 2018; Adjei et al. 2017). The difference in the magnitude of the association for men and women varies cross-nationally with larger gender differences in self-reported general health reported for Italy, Spain and Germany compared to the USA and the UK (Adjei et al. 2017). However, time in paid work is only associated with good self-reported general health among older men (Adjei et al. 2017) and women who allocate a large amount of time to housework combined with small amounts of sleep report poorer health (Adjei and Brand 2018).

\subsection{Cross-National Variation and Country Context}

The above implies that the time older people allocate to active participation and the associated health and well-being outcomes vary cross-nationally (Adjei et al. 2017). This suggest that how older people spend their time is influenced by national characteristics including social and economic policy frameworks. Generous public pensions as reward of long service lead to older people retiring from the labor market sooner, whereas means-tested basic pensions and market-based supplementary pensions might keep older people longer in the labor market (OECD 2019). The latter form of commodification might also increase participation in informal care and volunteering, because this form of active participation serves as a substitute for government programs (Musick and Wilson 2007). Extensive public services which reduce reliance upon family support and care provision in combination with employment impeding policies also keep employment rates high at older ages (Kim 2009; Schils 2008). Such a high degree of de-familialization not only promotes gender equality in paid and unpaid work (Lewis 2018) but also encourages older people's involvement in formal care (Saraceno and Keck 2010), because it results in high importance of formal social capital (e.g. social networks based on civic participation). This, in turn, results in more institutional opportunities for active participation (Pichler and Wallace 2007). In return, when social support and care is provided privately within the family as a result of a high degree of familialization participation in informal care increases (Saraceno and Keck 2010). So does gender inequality in active participation, because family support and care are mainly provided by women (Lewis 2018), which continues at later ages (Adjei and Brand 2018). In summary, Strauss and Trommer (2018) conclude that "well developed welfare state provisions tend to 'crowd in' more productive activities of the elderly" (p. 325).

In this paper we look at active participation among the elderly in Belgium and the USA. The countries' institutional context varies in ways that might affect time allocation to active participation.

Belgium. Social rights are largely tied to employment, and social security benefits transferred to the family through working partner(s) (historically the male breadwinner). This makes family trajectories, i.e., the sequence of family events over the life course such as union formation, childbearing and work status, an important determinant of income at older age (Dewilde 2012). Contributions to state pension funds are compulsory and Belgium has a means-tested income guarantee for the elderly. Early retirement is common in Belgium. The normal retirement age is 65 , but the effective retirement age is 61.6 for men and 60.5 for women in 2018. Net pension replacement rate from public scheme for a fullcareer average-wage worker equals 66.2\% (OECD 2019). Since 2019, Belgium has special paid leave with protection against dismissal to provide informal care for one month and with a maximum of six months over the working career. This fits within the Belgian policy 
to further expand home care and thus postpone the admission of elderly people in residential care centers as much as possible. Not-for-profit services such as associations are largely supported by public funds, which reduces the reliance on private donations and volunteers. A module on volunteering attached to the Belgian labor force survey of 2015 reveals that $18.8 \%$ of Belgians aged 65 years and over were involved in formal volunteering and $20.9 \%$ in informal care in the last twelve months preceding the survey (Hustinx et al. 2015). This ranks Belgium 15th among the 28 EU countries (EUROSTAT 2015). Older people in Belgium mainly volunteer for socio-cultural, educational and religious organizations (Hustinx et al. 2015).

The USA. The USA is a liberal welfare state. Despite state-level variation in the dominance of neo-liberal and conservative political ideologies, the USA distinguishes itself from other welfare states due to its low level of state intervention, leaving social welfare provision mainly to the market. Publicly provided pensions have a progressive benefit formula and a means-tested Supplementary Security Income (SSI) for older people. Net pension replacement rate from public scheme for a full-career average-wage worker equals $49.4 \%$. As a result, private pensions play an important role in providing old-age income in the USA, but with only half of the working age population contributing to private pension schemes, the relative old-age income poverty rate in the USA is high (OECD 2019). The normal retirement age is 66 years, but the effective retirement age of American men and women is above that (67.9 and 66.5 years, respectively).

In the USA, not-for-profit organizations rely heavily on private donations and volunteers. Volunteering is deeply rooted in American culture (Perry 2004). In 2015, about a quarter of Americans aged 65 years and over was involved in formal volunteering, mainly in civic, political, social and religious organizations (Bureau of Labor Statistics 2016). The American Association of Retired Persons (AARP) estimated that in 2015 that $14 \%$ of Americans provide informal care; one in three of these was 65 years or older (National Alliance for Caregiving 2015).

\subsection{Research Focus and Expectations}

Our study focusses on older people's active participation and well-being. We use a general measure of life satisfaction as an indicator of well-being (Linton et al. 2016). The research questions are as follows:

1. To what extent do older people participate in active participation and how much time do they spend on paid employment, unpaid work, informal help and volunteering?

2. Is spending time in active participation associated with older people's well-being?

3. Do associations between older people's time in active participation and their well-being differ between Belgium and the USA?

Based on the literature discussed above, we expect older people's time spent on paid employment, unpaid work, informal help and volunteering to be small both in total amount and in their share relative to the rest of the working population in both countries. We expect older people in the USA to spend more time on all four activities than older people in Belgium, as a consequence of the limited welfare provided in the USA. Consequently, in the USA, we expect a negative association between the more time older people spend on paid employment, unpaid work and informal help and well-being. In both countries we expect 
a positive association between the time spent on volunteering and well-being, but we also expect the association to be larger in Belgium than in the USA.

\section{Method}

\subsection{Data and Sample}

How people spend their time is studied by using time-diaries. In time-diaries people record their daily activities in a detailed way for at least $24 \mathrm{~h}$. As a result, time-diaries provide accurate estimates of people's daily life (Robinson and Godbey 2010). How people live their daily lives is important indicator of quality of life.

We use data from nationally representative time-use surveys (TUS) conducted by Statistics Belgium (STATBEL) and by the Bureau of Labor Statistics (BLS) in 2013. The BLS conducts TUS on a yearly basis, but the 2013 American Time Use Survey (ATUS) is the latest to include the well-being module and matches the survey year of the most recent Belgian Time Use Survey (BTUS). The BTUS follows the Harmonized European Time Use Survey guidelines (EUROSTAT 2009). Both surveys use time-diaries to record people's activities over the course one random day of the week (ATUS) or one random weekday and one random weekend day (BTUS). The ATUS uses computer-assisted telephone interviews to reconstruct a respondent's day in open time intervals (so-called yesterday recall method), whereas the BTUS uses paper diaries in which respondents record their activities in 10-min intervals. Additionally, the ATUS surveys only one individual per household, whereas the BTUS surveys all individuals within the household aged 10 years or over. Long fieldwork periods in both TUS account for seasonality. The ATUS is linked to the current population survey (CPS), the BTUS to the labour force survey (LFS). Time-use diaries are considered the most reliable way to collect comparable estimates of time-use (Robinson and Godbey 2010). We post-harmonised the countries' activity codes for our analyses (coding details available on request). The acquired data did not have incomplete time-diaries. The analytic sample is restricted to respondents aged 65 to 80 years. The lower age limit is set in line with the normal age of labour market exit in Belgium (OECD 2019). The upper age limit is set in line with data availability in the ATUS. Table 1 gives an overview of the sample characteristics.

\subsection{Dependent Variables}

To capture active participation, we calculate the time older people spend on paid employment, unpaid work, informal help and volunteering. Paid employment includes the time spent on main and/or second job and all activities related to being employed such as work-related travel, breaks and training. Time spent commuting is excluded. Unpaid work includes time spent on routine housework (e.g. cooking, cleaning, doing the laundry), on gardening and maintenance, and household management. Informal help includes time spent on informal child- or adult-care and help both within and outside the household. Volunteering includes time spent on administrative, formal care, public health and maintenance support activities and other voluntary activities related to associations. Travel time for active participation is not included.

We use a general measure of life satisfaction as an indicator of well-being. The Belgian TUS uses the Satisfaction With Life scale (SWL) (Diener et al. 1985). The SWL 
Table 1 Sample characteristics by country

\begin{tabular}{|c|c|c|}
\hline & Belgium & USA \\
\hline Diary days (n) & 1384 & 2133 \\
\hline \multicolumn{3}{|l|}{$\operatorname{Sex}(\%)$} \\
\hline Female & 47.8 & 58.9 \\
\hline Male & 52.2 & 41.1 \\
\hline \multicolumn{3}{|l|}{ Age $(\%)$} \\
\hline $65-69$ years & 46.7 & 38.8 \\
\hline 70-74 years & 31.5 & 24.9 \\
\hline $75-80$ years & 21.8 & 36.3 \\
\hline Higher education (\%) & 27.9 & 31.4 \\
\hline Partner $(\%)$ & 78.7 & 43.8 \\
\hline \multicolumn{3}{|l|}{ Annual family income $(\%)^{\mathrm{a}}$} \\
\hline Lowest income group & 17.2 & 17.8 \\
\hline Middle income group & 64.9 & 65.6 \\
\hline Highest income group & 17.9 & 16.6 \\
\hline \multicolumn{3}{|l|}{ Life satisfaction score } \\
\hline Satisfaction with Life (score between $0-10)^{b}$ & & 7.4 \\
\hline \multicolumn{3}{|l|}{ Satisfaction with Life Scale $(\%)^{\mathrm{c}}$} \\
\hline Extremely dissatisfied & 0.2 & \\
\hline Dissatisfied & 3.0 & \\
\hline Slightly dissatisfied & 10.5 & \\
\hline Neutral & 18.5 & \\
\hline Slightly satisfied & 32.7 & \\
\hline Satisfied & 30.6 & \\
\hline Extremely satisfied & 4.5 & \\
\hline
\end{tabular}

${ }^{a}$ Lowest income group earning less than 18,000 EUR per year in Belgium or less than 15,000 USD per year in the USA; highest income group earning more than 37,200 EUR per year in Belgium or more than 75,000 USD per year in the USA.

${ }^{\text {b} C a n t r i l ' s ~ L a d d e r ~ t e c h n i q u e ~(C a n t r i l ~ 1965) . ~}$

${ }^{\mathrm{c}}$ Diener et al. (1985)

combines scores on 5 Likert type items to construct a 7-point Likert scale of SWL distinguishing between extremely dissatisfied, dissatisfied, slightly dissatisfied, neutral, slightly satisfied, satisfied and extremely satisfied. A flag procedure was used to replace missing values with means for cases having at least three non-missing values on all five items. The SWL scale in the Belgian TUS has a Cronbach's alpha of 0.89 for the selected sample. The American TUS uses the Cantril's Ladder technique (Cantril 1965) and have individuals answer to the question: Please imagine a ladder with steps numbered from zero at the bottom to ten at the top. The top of the ladder represents the best possible life for you and the bottom of the ladder represents the worst possible life for you. If the top step is 10 and the bottom step is 0 , on which step of the ladder do you feel you personally stand at the present time? Although both life satisfaction scales are different, Helliwell et al. (2019) report a correlation of 0.88 between both scales based on cross-sectional data from the European Social Survey and the Gallup World Poll. 


\subsection{Analysis Plan}

First, we present a descriptive overview of active participation of older people aged 65-80 in the USA and in Belgium using three indicators. First, we present the average time spent on paid employment, unpaid work, informal help and volunteering for the whole sample (i.e. duration per respondent). Second, we present the percentage of older people that participated in these activities (i.e. participation rate). Third, we calculate the time participants spent on active participation (i.e. duration per participant). We use Student t-tests to compare differences in the amount of time spent between the two countries within ages and chi-square tests to compare differences in the participation rates between the two countries. Data are weighted to match the weekly distribution of weekdays (Monday-Friday) and weekend days (Saturday-Sunday).

Next we investigate older people's share in each countries' total daily time spent on paid employment, unpaid work, informal help and volunteering by dividing it into the share done by 65 to 80 -year-olds and the share done by the remaining working population (15 to 64-year olds by definition of the OECD).

Finally, we use linear regression to determine associations between time allocated to paid employment, unpaid work, informal help and volunteering, and life satisfaction. We do this separately for each country. We treat the SWL Likert scale and the Cantril's Ladder score as interval data (see Allen and Seaman 2007 for Likert scale; see Palmore and Luikart 1972 for Cantril's Ladder). We use the formula proposed by Paternoster et al. (1998) to test for the equality of regression coefficients between the two countries.

In the models, we control for sex (dummy for female) and age, through a categorical variable distinguishing between 65-69-year-olds (omitted), 70-74-year-olds, and 75-80-yearolds. We also control for education (dummy for having achieved higher education), partner (dummy for having a partner, either married or cohabiting, in the household), and annual household income through a categorical variable distinguishing between lowest income group ( $20 \%$ of sample earning less than 18,000 EUR per year in Belgium or less than 15,000 USD per year in the USA), highest income group ( $20 \%$ of sample earning more than 37,200 EUR per year in Belgium or more than 75,000 USD per year in the USA), and a middle income group (omitted). In both countries, household income is net and is the sum of all family members' wages, net income from business, farm or rent, pensions, dividends, interest, and social security payments. We also enter interactions between time allocation and age and time allocation and sex. We tested other interaction terms but this did not improve the models and therefore these interactions are not retained in the final model.

\section{Results}

\subsection{Time Spent on Active Participation}

On average older people aged between 65 and 80 years in Belgium spend 211.7 min $(\sim 3.5 \mathrm{~h})$ per day on active participation (see Table 2$)$. Most of it is spent on unpaid work (188.9 min or $3 \mathrm{~h}$ per day). Less than 10 min per day are spent on volunteering and less than 7 min per day on paid employment and informal help. Their American counterparts spend a little more time on active participation (218.4 min or $~ 3.6 \mathrm{~h}$ per day). Although American older people spend almost an hour (51.9 min) per day less than Belgians on 
Table 2 Participation rate and time spent on active participation by older people (65-80 years) in Belgium and the USA

\begin{tabular}{lccc}
\hline & \multicolumn{2}{c}{ Duration per respondent [min./day] } & \\
\cline { 2 - 4 } & Belgium & USA & Difference \\
\hline Paid employment & 6.6 & 49.0 & $42.4^{* * *}$ \\
Unpaid work & 188.9 & 137.0 & $51.9^{* * *}$ \\
Informal help & 6.6 & 17.0 & $10.4^{* * *}$ \\
Volunteering & 9.6 & 15.4 & $5.8^{* * *}$ \\
Total & 211.7 & 218.4 & $6.7^{*}$ \\
\hline & Participation rate [\%] & & \\
\cline { 2 - 4 } & Belgium & USA & Difference \\
\hline Paid employment & 2.9 & 12.4 & $9.5^{* * *}$ \\
Unpaid work & 94.3 & 83.5 & $10.8^{* * *}$ \\
Informal help & 5.3 & 18.5 & $13.2^{* * *}$ \\
Volunteering & 5.8 & 9.1 & $3.3^{* * *}$ \\
Total & 95.0 & 88.8 & $6.2^{* * *}$ \\
\hline & Duration per participant [min./day] & \\
\cline { 2 - 4 } & Belgium & USA & Difference \\
\hline Paid employment & 225.9 & 395.1 & $169.2^{* * *}$ \\
Unpaid work & 200.3 & 164.1 & $36.2^{* * *}$ \\
Informal help & 125.8 & 92.2 & $33.6^{* * *}$ \\
Volunteering & 166.1 & 245.2 & $3.9^{\text {n.s }}$ \\
Total & 222.8 & $22.4^{* * *}$ \\
\hline & & & \\
\hline
\end{tabular}

Data are weighted to match the weekly distribution of weekdays (Monday-Friday) and weekend days (Saturday-Sunday).

Levels of significance: $* * * p \leq 0.001, * * p \leq 0.01, * p \leq 0.05$, n.s. not significant

unpaid work, this difference is annulled by significantly more time spent on paid employment (42.4 min per day more) and informal help (10.4 min per day more). Older people in America also spend significantly more time on volunteering (average $15.4 \mathrm{~min}$ per day) than do Belgians. In both countries the correlations between time spent on paid employment and unpaid work on the one hand and informal help and volunteering on the other are negligible $(\mathrm{r}<0.10)$.

When we look at the participation rate, we find that on an average day, $95 \%$ of the elderly in Belgium and $88.8 \%$ of the elderly in the USA spend time in active participation (see Table 2). This mainly reflects high participation rates for unpaid work. Participation rates for the other activities are much lower. Nevertheless, a significantly larger share of older Americans spend time on paid employment than older Belgians (12.4\% vs. 2.9\%). The difference in the participation rate for informal help is the largest (a difference of $13.2 \%$ ). In both countries less than one in ten older people participate in volunteering.

Despite the lower rate of volunteering of Belgian elderly, those who do participate report doing about $2.8 \mathrm{~h}$ on an average day, which is not significantly different from their American counterparts (166.1 and 170 min per day, respectively) (see Table 2). Moreover, 
the substantially fewer Belgian older people that participate in informal help, allocate a significant half an hour per day more to it than the American participants do (125.8 and $92.2 \mathrm{~min}$ per day respectively). This is also true for unpaid work. On the other hand, American older people who participate in paid employment, do so for almost $3 \mathrm{~h}$ per day more than their Belgian counterparts (395.1 and 225.9 min per day, respectively).

Figure 1 breaks the time spent in active participation down by country and age. It shows the average amount of time (in minutes) spent on paid employment, unpaid work, informal help and volunteering by people aged between 65 and 80 years in Belgium (left hand side) and the USA (right hand side). As suggested by the difference in effective retirement age between Belgium and the USA, the descriptive results show that older people in the US spend significantly more time on paid employment across all ages, with only a few exceptions. In contrast, Belgian older people spend more time on unpaid work across all ages, again with a few exceptions. Although the differences are much smaller than the differences in paid employment and unpaid work, American older people up to their late seventies spend more time on informal help than their Belgian equivalents. Older Belgians and Americans hardly differ in time spent volunteering across ages except the mid- and late seventies.

To put the descriptive results in more perspective, we compare older people's time in paid employment, unpaid work, informal help and volunteering with the time spent in these activities by the rest of the working age population (15 to 64-year-olds by definition of the OECD). For each activity, Fig. 2 divides the total time (100\%) spent by 15 to 80 -year-olds into the share of 15 to 64 -year-olds and the share of 65 to 80 -year-olds. Figure 2 shows that whilst the share of older people's time in paid employment is almost four times larger in the USA than in Belgium, compared to the rest of the working population, these shares are small in both countries ( $4.8 \%$ and $0.6 \%$ respectively). Older people's share of total unpaid work is just over one fifth. The largest country difference is found for older people's share in informal help. Despite that fewer Belgian older people participate in informal help (see Table 2) their share in the nation's total time spent on this activity is $20.6 \%$. This is substantially more than the share of their American counterparts (7.7\%). Similarly, despite the small participation rates in volunteering, the share of Belgian older people in their nation's time allocated to volunteering is $21.4 \%$. The share done by older Americans is even larger at $32.6 \%$.

Descriptive results suggest that at older age, Belgians' active participation is more comprised of unpaid work whereas Americans' active participation consists of more paid employment, informal help and volunteering. Nevertheless, the time older people allocate to informal help and volunteering, is a substantial share of both nations' total time allocated to these forms of active participation.

\subsection{Active Participation and Life Satisfaction}

We next use multivariate analyses to test whether time spent on paid employment, unpaid work, informal help and volunteering is related to life satisfaction (see Table 3). In both models, the intercept represents the reference group of less than higher educated, 65 to 69 -year-old men living without a partner with a household income in the middle-income group. The intercept in the model for Belgium shows that net of covariates this reference group rates their life satisfaction 4.3 on scale of 1 to 7 , which corresponds to a rating between neutral and slightly satisfied. The intercept in the model for the USA shows a life satisfaction score of 6.8 on a scale of 0 to 10 for this reference group. Although the two 

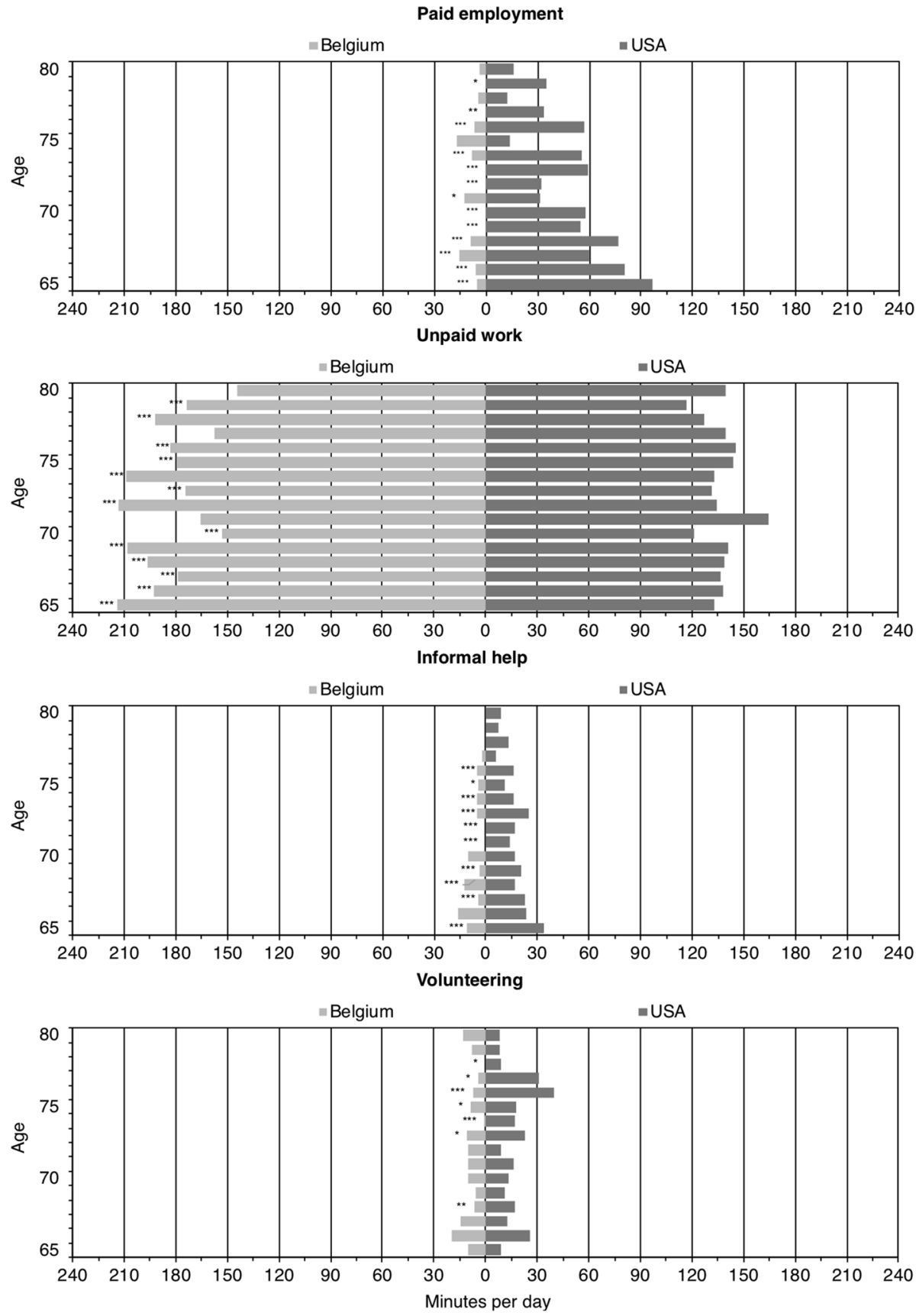

Fig. 1 Time spent on paid employment, unpaid work, informal help and volunteering by older people (6080 years) in Belgium and the USA (minutes per day) 


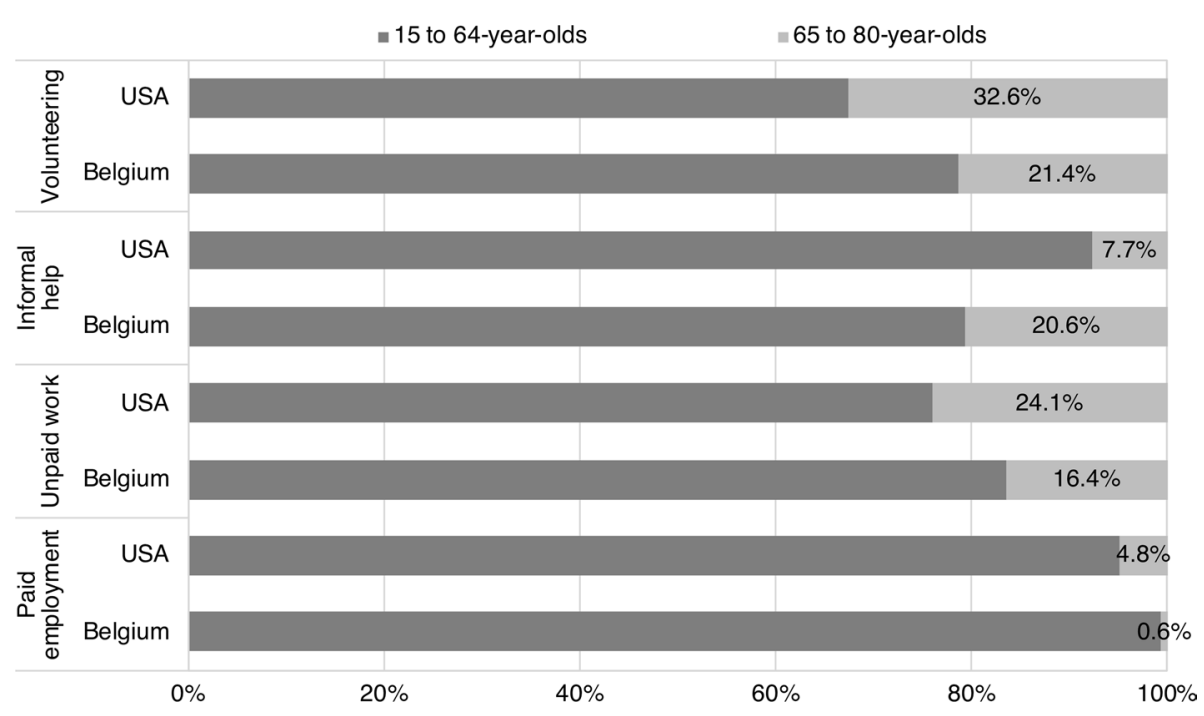

Fig. 2 Relative shares of time spent on paid employment, unpaid work, informal help and volunteering by older people (65-80 years) and working population (15-64 years) in Belgium and the USA

scales are not perfectly comparable, the reference groups in both countries rate their life satisfaction just above the midpoint of the scale used.

The results for time spent in active participation show that only the time spent on paid employment relates to life satisfaction in both countries. It does so negatively in Belgium and positively in the USA. In addition, time spent on informal help in Belgium is also negatively associated with life satisfaction, but not in the USA. Conversely, the time spent on volunteering is negatively related to life satisfaction in the USA, but not in Belgium.

The control variable sex shows that in Belgium women rate their life satisfaction lower than men rate theirs. The opposite is true in the USA. Having completed higher education relates positively to life satisfaction in Belgium but not in the USA. In the USA, older age groups rate their life satisfaction higher than the reference group (64-69 years) with 70 to 74-year-olds having the highest life satisfaction score. Conversely, in Belgium this age group reports the lowest life satisfaction score. Belgian 64 to 69 -year-olds and 75 to 80 -year-olds do not differ significantly in their life satisfaction score. Having a partner, and having a high household income are both also positively associated with life satisfaction. Being in the $20 \%$ lowest income group relates to lower life satisfaction in the USA only.

For ease of interpretation, the interaction terms between (1) time allocation and age, and (2) time allocation and sex are plotted in Fig. 3. The thin, dark grey lines indicate the association between life satisfaction and age (upper panel) and life satisfaction and sex (lower panel) respectively. If the lines for time allocation are higher or lower than this line for one category compared to another, then there is an additional positive or negative association between time allocation and life satisfaction for that category.

The interaction of time in active participation and age show that there is an additional positive association between older people's time spent on paid employment and unpaid work with life satisfaction compared to the reference age group (see Fig. 3). However, for 70 to 74-year-old Belgians, the additional positive association of time spent on paid employment does not overcome the negative associations between paid employment and 
Table 3 Coefficients and standard errors from OLS regression models predicting life satisfaction of older people (65-80 years) on an average day of the week in Belgium and the USA

\begin{tabular}{|c|c|c|c|c|c|c|c|c|}
\hline & \multicolumn{4}{|c|}{ Belgium } & \multicolumn{4}{|l|}{ USA } \\
\hline & $B$ & S.E. & Beta & Sig. & $B$ & S.E. & Beta & Sig. \\
\hline Intercept & 4.32 & 0.07 & & $* * *$ & 6.79 & 0.09 & & $* * *$ \\
\hline \multicolumn{9}{|l|}{ Active participation } \\
\hline Paid employment [hrs/day] & -0.07 & 0.03 & -0.05 & $*$ & 0.04 & 0.02 & 0.04 & $*$ \\
\hline Unpaid work [hrs/day] & -0.01 & 0.01 & -0.01 & & 0.02 & 0.02 & 0.02 & \\
\hline Informal help [hrs/day] & -0.11 & 0.03 & -0.07 & $* * *$ & 0.06 & 0.05 & 0.03 & \\
\hline Volunteering [hrs/day] & 0.04 & 0.03 & 0.03 & & -0.08 & 0.04 & -0.04 & $*$ \\
\hline \multicolumn{9}{|l|}{ Individual and household variables } \\
\hline Sex $($ ref. $=$ men $)$ & -0.18 & 0.07 & -0.08 & $* *$ & 0.18 & 0.08 & 0.04 & $*$ \\
\hline \multicolumn{9}{|l|}{ Age (ref. $=65-69$ years) } \\
\hline $70-74$ years & -0.23 & 0.07 & -0.09 & $* * *$ & 0.44 & 0.11 & 0.09 & $* * *$ \\
\hline $75-80$ years & -0.05 & 0.09 & -0.02 & & 0.33 & 0.10 & 0.07 & $* * *$ \\
\hline Higher education $($ ref. $=$ no $)$ & 0.13 & 0.04 & 0.05 & $* * *$ & 0.02 & 0.06 & 0.01 & \\
\hline Partner (ref. $=$ no) & 0.69 & 0.05 & 0.24 & $* * *$ & 0.46 & 0.06 & 0.10 & $* * *$ \\
\hline \multicolumn{9}{|l|}{ Income $($ ref. $=$ Middle $60 \%)$} \\
\hline Lowest $20 \%$ & 0.15 & 0.06 & 0.05 & $* *$ & -0.40 & 0.08 & -0.07 & $* * *$ \\
\hline Highest $20 \%$ & 0.31 & 0.05 & 0.09 & $* * *$ & 0.39 & 0.08 & 0.07 & $* * *$ \\
\hline \multicolumn{9}{|l|}{ Interactions } \\
\hline \multicolumn{9}{|l|}{ Active participation by age (ref. $=65-69$ years) } \\
\hline Paid employment by $70-74$ years [hrs/day] & 0.13 & 0.05 & 0.05 & $* *$ & 0.09 & 0.03 & 0.05 & $* * *$ \\
\hline Paid employment by $75-80$ years [hrs/day] & 0.22 & 0.06 & 0.06 & $* * *$ & -0.02 & 0.03 & -0.01 & \\
\hline Unpaid work by $70-74$ years [hrs/day] & 0.07 & 0.02 & 0.12 & $* * *$ & -0.07 & 0.03 & -0.05 & * \\
\hline Unpaid work by $75-80$ years [hrs/day] & 0.05 & 0.02 & 0.07 & * & -0.08 & 0.03 & -0.06 & $* *$ \\
\hline Informal help by $70-74$ years [hrs/day] & 0.03 & 0.07 & 0.01 & & -0.27 & 0.06 & -0.07 & $* * *$ \\
\hline Informal help by $75-80$ years [hrs/day] & -0.03 & 0.10 & -0.01 & & 0.01 & 0.07 & 0.00 & \\
\hline Volunteering by $70-74$ years [hrs/day] & -0.05 & 0.05 & -0.02 & & 0.25 & 0.07 & 0.06 & $* * *$ \\
\hline Volunteering by $75-80$ years [hrs/day] & 0.42 & 0.07 & 0.10 & $* * *$ & 0.19 & 0.05 & 0.07 & $* * *$ \\
\hline \multicolumn{9}{|l|}{ Active participation by sex $($ ref. $=$ men $)$} \\
\hline Paid employment by women [hrs/day] & 0.02 & 0.06 & 0.01 & & -0.02 & 0.02 & -0.01 & \\
\hline Unpaid work by women [hrs/day] & 0.01 & 0.01 & 0.01 & & 0.08 & 0.02 & 0.08 & $* * *$ \\
\hline Informal help by women [hrs/day] & 0.21 & 0.06 & 0.09 & $* * *$ & 0.02 & 0.05 & 0.01 & \\
\hline Volunteering by women [hrs/day] & -0.05 & 0.06 & -0.02 & & 0.07 & 0.05 & 0.02 & \\
\hline Adjusted $\mathrm{R}^{2}$ & 0.10 & & & & 0.05 & & & \\
\hline
\end{tabular}

$B$ Unstandardized coefficient, S.E. Standard error of unstandardized coefficient, Beta Standardized coefficient, Sig. Significance

older age and the dependent variable life satisfaction $(-0.07+-0.23+0.13=-0.17$; see Table 3). In the USA, time spent on paid employment by the middle age group adds to the positive association between paid employment and age and the dependent variable life satisfaction, whereas time spent on unpaid work mitigates these associations. The time 70 to 74-year-old Americans spend on informal help substantially lessens their positive association with life satisfaction. Finally, in both countries, time spent on volunteering 
5

Belgium
USA

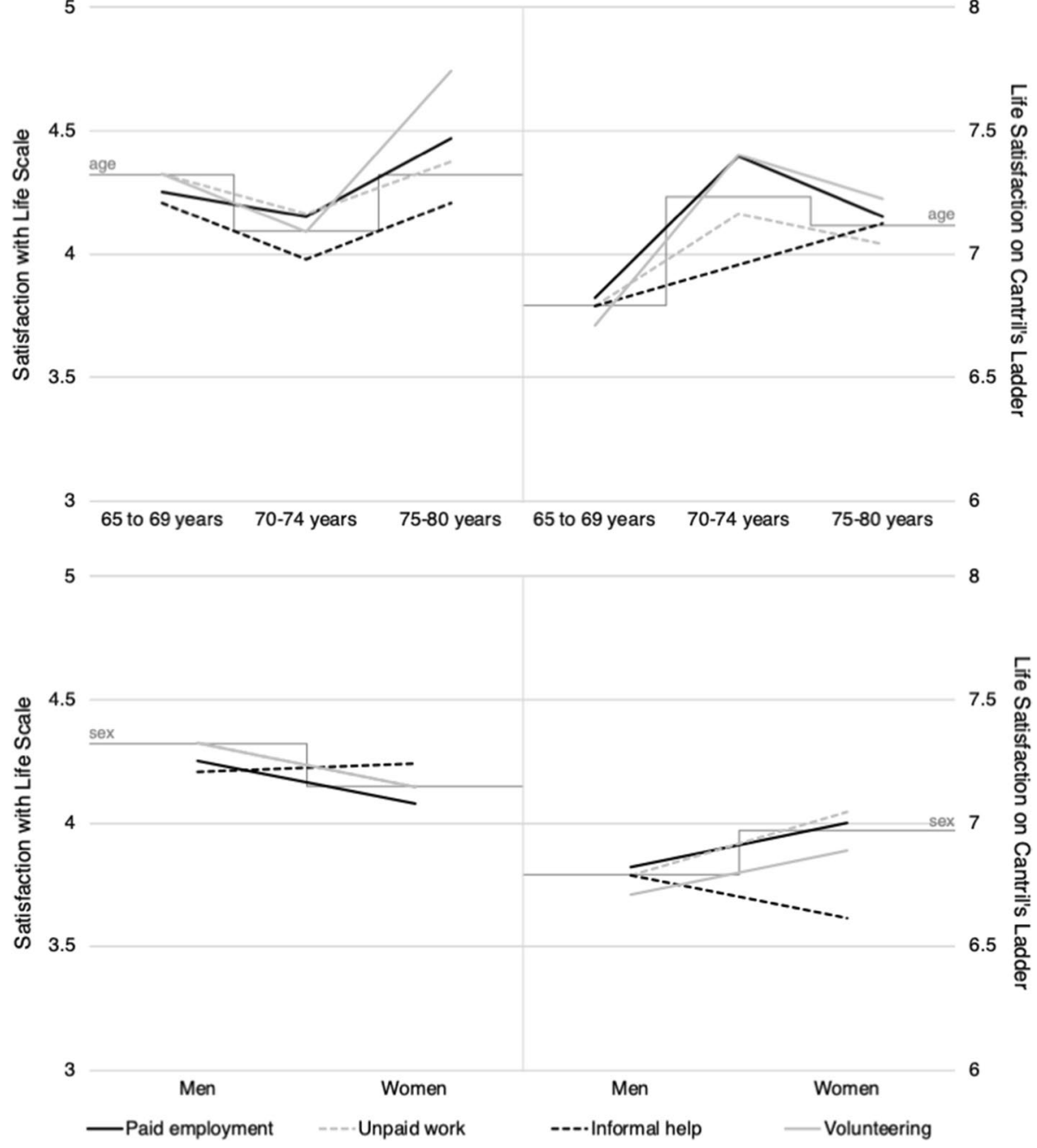

Fig. 3 Difference across age and sex in life satisfaction for time allocation to active participation of older people (65-80 years) in Belgium and the USA. Note. Calculated from the results of Table 3. Life satisfaction for 65 to 69 -year-olds and for men is equal to the intercept and scores for life satisfaction and time allocation is calculated by summing the intercept and the significant main term for paid employment, unpaid work, informal help and volunteering, respectively; life satisfaction scores for other categories are calculated by summing the intercept and significant main terms for age or sex and time allocation and significant interaction between age or sex and time allocation

is associated with a substantially higher life satisfaction for the oldest age groups, and a higher life satisfaction of the middle age group in the USA only (see Fig. 3).

The interaction terms of time spent in active participation and sex show that women's time spent on informal help is positively associated with life satisfaction in Belgium (see Fig. 3), but this association does not overcome the negative main association between sex and informal help and the dependent variable life satisfaction $(-0.11+-0.18+0.21=$ 
-0.08 ; see Table 3). In the USA, women's time spent on unpaid work slightly increases women's life satisfaction score.

\section{Discussion}

The aim of this study was to use time-diaries to examine older people's active participation and well-being, measured by a general measure of life satisfaction. As opposed to categorical measures of active participation over a longer recall period, time-diaries provide close to real-time information, i.e., recorded when activities take place or shortly after, about people's daily life. We used nationally representative time-use data from Belgium and the USA to investigate whether the time older people spend on paid employment, unpaid work, informal help and volunteering and the association between their time allocation and their life satisfaction differed by institutional context. Reflecting this, we found that older people in Belgium, who can rely on more generous state-provided pensions and early retirement options, exited the labour market much earlier and spend much less time on paid employment than older people in the USA, who need to rely more on the market for their income. Older people in the USA still spend a substantial amount of time in paid employment until their late 70s. Furthermore, in line with previous research (Adjei et al. 2017), time spent on paid employment was positively associated with life satisfaction, especially in the 70 to 74-year-old age group in the USA.

The comparatively early retirement age in Belgium suggest more could be available to volunteer. However, despite the finding that retirees generally have retirement plans consistent with the active ageing perspective (Principi et al. 2018), this potential in Belgium does not eventuate. Just below $6 \%$ of older Belgians recorded volunteering in their timediaries, compared to $10 \%$ of their American counterparts. America's deeply rooted volunteering culture might explain the difference. Similarly, the positive association between time spent volunteering and higher life satisfaction is much stronger in the USA than in Belgium (see also Hansen et al. 2018). This finding underlines the individual health benefits of volunteering (Halaweh et al. 2018). Additionally, volunteering increases the likelihood of use of preventive health care services as a result of social network formation, which might reduce long term health care costs (Kim and Konrath 2016). Governments and organizations would therefore do well to mobilization retirees into active participation. To do so, Dury et al. (2015) argue that organizations in Belgium must acknowledge that loss of social roles, smaller networks and fewer resources after retirement higher the burden of older people to start volunteering. However, if time spent on active participation of older people is largely the result of previous engagement (Di Gessa and Grundy 2017) governments could facilitate social engagement earlier in the life course.

Apart from volunteering, both countries indirectly rely on informal help in their attempt to encourage home care as means to postpone the admission of elderly people in residential care centers. Again, more older American elderly than older Belgians recorded time spent on informal help in their time-diaries. However, in both countries time spent on informal help associates negatively with life satisfaction (women in Belgium being the exception). This suggests that the institutional context creates an environment in which the need to provide informal care crowds out the altruistic attitudes (as suggested by Kahana et al. 2013), or social commitment (see for review Onyx and Warburton 2003) that give rise to providing informal help. Our findings are in line with findings that a too great dependence on grandparenting, as a form of informal help, can negatively affect grandparents' well-being 
(Craig and Jenkins 2016a, b). It is suggested that governments need to provide greater support for informal carers (Principi et al. 2018). It must be said that, at the end of 2019, the Belgian government introduced special paid leave with protection against dismissal to provide informal help.

This study was subject to a number of limitations. In this study we used a general measure of life satisfaction as an indicator of well-being that slightly varied between both countries. There seems to be no consensus on which indicator(s) to use (Linton et al. 2016), making comparisons not straightforward. To further isolate the association between the activities underlying active participation and well-being, it would also be preferable to use indicators of physical, mental and social well-being at level of the activity registration in the time-diary. Throughout the day, activities might have contradictory or enhancing effects on overall well-being. The data are cross-national so we cannot isolate causality, but report on associations only. Cross-national longitudinal time-use data are currently unavailable but were it to become so could analyse causality directly. This would allow contributing to debates on whether active participation improves well-being or whether well-being influences participation (as for example reported by Son and Wilson 2012). Engaging in paid employment, informal help and volunteering might become more occasional at later ages. Time-use surveys that survey one random weekday and on random weekend day (in case of Belgium) or one random day of the week (in case of the USA) might lead to underestimations of activities that are not done daily (Gershuny 2012). Time-use surveys that cover a longer registration period might counteract this.

\section{Conclusion}

Our findings indicate that the time older people spend in active participation is small, but their share of a nation's total time spent on volunteering is substantial. Our country comparison furthermore suggests that institutional context affects older people's time-use patterns and the associations with life satisfaction. Overall, the results do not show time spent on active participation to be common among older people in the two countries, suggesting that active participation might be the result of previous engagement (Di Gessa and Grundy 2017) and the association with life satisfaction should be interpreted in line with research suggesting that better subjective well-being makes people more active at older ages (Son and Wilson 2012).

How people spend their time tells a lot about the quality of their lives. Apart from how much time they spend on active participation, it can also tell how sedentary their time is, or how much time they spend in solitude or outdoors. Linking time-use patterns to subjective (and objective) measures of well-being increases the potential of time-use surveys for public health research (Bauman et al. 2019). A time-use perspective allows linking institutional opportunities and constraints to people's daily behavior. Cross-national comparisons thus allow analyzing how different institutional contexts affect people's lives differently. As this study has shown, studying older people's well-being from a time-use perspective proves fruitful and therefore needs further investigation.

\section{Compliance with Ethical Standards}

Conflict of interest The authors declare that they have no conflict of interest. 


\section{References}

Adjei, N. K., \& Brand, T. (2018). Investigating the associations between productive housework activities, sleep hours and self-reported health among elderly men and women in western industrialised countries. BMC public health, 18(1), 110.

Adjei, N. K., Brand, T., \& Zeeb, H. (2017). Gender inequality in self-reported health among the elderly in contemporary welfare countries: A cross-country analysis of time use activities, socioeconomic positions and family characteristics. PLOS ONE, 12(9), e0184676.

Allen, I. E., \& Seaman, C. A. (2007). Likert scales and data analyses. Quality Progress, 40(7), 64-65.

Arpino, B., \& Bordone, V. (2017). Regular provision of grandchild care and participation in social activities. Review of Economics of the Household, 15(1), 135-174.

Arts, W., \& Gelissen, J. (2010). Models of the welfare state. In F. Castles, S. Leibfried, J. Lewis, H. Obinger, \& C. Pierson (Eds.), The Oxford handbook of the welfare state (pp. 569-583). Oxford: Oxford University Press.

Bauman, A., Bittman, M., \& Gershuny, J. (2019). A short history of time use research; implications for public health. BMC public health, 19(2), 607.

Bird, C. E. (1999). Gender, household labor, and psychological distress: The impact of the amount and division of housework. Journal of health and social behavior, 40, 32-45.

Bureau of Labor Statistics. (2016). Economic news release: Volunteerin in the United States. Washington: United States Department of Labor.

Burr, J. A., Choi, N. G., Mutchler, J. E., \& Caro, F. G. (2005). Caregiving and volunteering: Are private and public helping behaviors linked? The Journals of Gerontology Series B: Psychological Sciences and Social Sciences, 60(5), S247-S256.

Burr, J. A., Mutchler, J. E., \& Caro, F. G. (2007). Productive activity clusters among middle-aged and older adults: Intersecting forms and time commitments. The Journals of Gerontology Series B: Psychological Sciences and Social Sciences, 62(4), S267-S275.

Cantril, H. (1965). Pattern of human concerns.

Choi, N. G., Burr, J. A., Mutchler, J. E., \& Caro, F. G. (2007). Formal and informal volunteer activity and spousal caregiving among older adults. Research on Aging, 29(2), 99-124.

Craig, L., \& Jenkins, B. (2016a). The composition of parents' and grandparents' child-care time: Gender and generational patterns in activity, multi-tasking and co-presence. Ageing \& Society, 36(4), 785-810.

Craig, L., \& Jenkins, B. (2016b). Grandparental childcare in Australia: Gender differences in the correlates of providing regular grandparental care while parents work. Community, Work \& Family, 19(3), 281-301.

Dewilde, C. (2012). Lifecourse determinants and incomes in retirement: Belgium and the United Kingdom compared. Ageing \& Society, 32(4), 587-615.

Di Gessa, G., \& Grundy, E. (2017). The dynamics of paid and unpaid activities among people aged 50-69 in Denmark, France, Italy, and England. Research on Aging, 39(9), 1013-1038.

Diener, E., Emmons, R. A., Larsen, R. J., \& Griffin, S. (1985). The satisfaction with life scale. Journal of Personality Assessment, 49(1), 71-75.

Dury, S., De Donder, L., De Witte, N., Buffel, T., Jacquet, W., \& Verté, D. (2015). To volunteer or not: The influence of individual characteristics, resources, and social factors on the likelihood of volunteering by older adults. Nonprofit and Voluntary Sector Quarterly, 44(6), 1107-1128.

European Commission (2018). The 2018 ageing report. Economic and budgetary projections for the EU member states (2016-2070). Luxembourg: Publications Office of the European Union.

EUROSTAT (2009). Harmonised European time use surveys. Guidelines 2008. Luxembourg: Office for Official Publications of the European Communities.

EUROSTAT. (2015). Social participation and intergration statistics. Luxembourg: European Commission.

Gauthier, A. H., \& Smeeding, T. M. (2003). Time use at older ages: Cross-national differences. Research on Aging, 25(3), 247-274.

Gershuny, J. (2012). Too many zeros: A method for estimating long-term time-use from short diaries. Annals of Economics and Statistics. https://doi.org/10.2307/23646464.

Halaweh, H., Dahlin-Ivanoff, S., Svantesson, U., \& Willén, C. (2018). Perspectives of older adults on aging well: A focus group study. Journal of Aging Research, 2018. https://doi.org/10.1155/2018/9858252.

Hank, K., \& Stuck, S. (2008). Volunteer work, informal help, and care among the 50 in Europe: Further evidence for 'linked'productive activities at older ages. Social Science Research, 37(4), 142-107.

Hansen, T., Aartsen, M., Slagsvold, B., \& Deindl, C. (2018). Dynamics of volunteering and life satisfaction in midlife and old age: Findings from 12 European countries. Social Sciences, 7(5), 78.

Helliwell, J. F., Huang, H., \& Wang, S. (2019). Changing world happiness. In J. F. Helliwel, R. Layard, \& J. Sachs (Eds.), The world happiness report. New York: Sustainable Development Solutions Network. 
Hook, J. (2004). Reconsidering the division of household labor: Incorporating volunteer work and informal support. Journal of Marriage and Family, 66(1), 101-117.

Horsfall, B., \& Dempsey, D. (2015). Grandparents doing gender: Experiences of grandmothers and grandfathers caring for grandchildren in Australia. Journal of Sociology, 51(4), 1070-1084.

Hustinx, L., Marée, M., De Keyser, L., Verhaeghe, L., \& Xhauflair, V. (2015). Het vrijwilligerswerk in België. Kerncijfers. Brussels: Koning Boudewijn Stichting.

Jenkinson, C. E., Dickens, A. P., Jones, K., Thompson-Coon, J., Taylor, R. S., Rogers, M., et al. (2013). Is volunteering a public health intervention? A systematic review and meta-analysis of the health and survival of volunteers. BMC Public Health, 13(1), 773.

Kahana, E., Bhatta, T., Lovegreen, L. D., Kahana, B., \& Midlarsky, E. (2013). Altruism, helping, and volunteering: Pathways to well-being in late life. Journal of Aging and Health, 25(1), 159-187.

Kim, E. S., \& Konrath, S. H. (2016). Volunteering is prospectively associated with health care use among older adults. Social Science \& Medicine, 149, 122-129.

Kim, J. (2009). Early retirement in the three types of welfare states. Research on Aging, 31(5), 520-548.

Lewis, J. (2018). Gender, social care and welfare state restructuring in Europe. London: Routledge.

Linton, M.-J., Dieppe, P., \& Medina-Lara, A. (2016). Review of 99 self-report measures for assessing wellbeing in adults: exploring dimensions of well-being and developments over time. British Medical Journal Open, 6(7), e010641.

López-López, R., \& Sánchez, M. (2020). The institutional active aging paradigm in Europe (2002-2015). The Gerontologist, 60(3), 406-415.

Matz-Costa, C., Carr, D. C., McNamara, T. K., \& James, J. B. (2016). Physical, cognitive, social, and emotional mediators of activity involvement and health in later life. Research on Aging, 38(7), 791-815.

McKenna, K., Broome, K., \& Liddle, J. (2007). What older people do: Time use and exploring the link between role participation and life satisfaction in people aged 65 years and over. Australian Occupational Therapy Journal, 54(4), 273-284.

McMunn, A., Nazroo, J., Wahrendorf, M., Breeze, E., \& Zaninotto, P. (2009). Participation in socially-productive activities, reciprocity and wellbeing in later life: Baseline results in England. Ageing \& Society, 29(5), 765-782.

Moss, M. S., \& Lawton, M. P. (1982). Time budgets of older people: A window on four lifestyles. Journal of Gerontology, 37(1), 115-123.

Musick, M. A., \& Wilson, J. (2007). Volunteers: A social profile. Bloomington: Indiana University Press.

Mutchler, J. E., Burr, J. A., \& Caro, F. G. (2003). From paid worker to volunteer: Leaving the paid workforce and volunteering in later life. Social Forces, 81(4), 1267-1293.

National Alliance for Caregiving. (2015). Caregiving in the US.. Washington DC: AARP Public Policy Institute.

OECD (2018). Life expectancy at 65 (Indicator). doi:10.1787/0e9a3f00-en.

OECD. (2019). Pensions at a glance 2019. OECD and G20 Indicators. Paris: OECD Publishing.

Onyx, J., \& Warburton, J. (2003). Volunteering and health among older people: A review. Australasian Journal on Ageing, 22(2), 65-69.

Palmore, E., \& Luikart, C. (1972). Health and social factors related to life satisfaction. Journal of Health and Social Behavior, 13(1), 68-80.

Papa, R., Cutuli, G., Principi, A., \& Scherer, S. (2019). Health and volunteering in Europe: A longitudinal study. Research on Aging. https://doi.org/10.1177/0164027519834939.

Paternoster, R., Brame, R., Mazerolle, P., \& Piquero, A. (1998). Using the correct statistical test for the equality of regression coefficients. Criminology, 36(4), 859-866.

Perry, J. L. (2004). Civic service in North America. Nonprofit and Voluntary Sector Quarterly, 33(4_suppl), $167 \mathrm{~S}-183 \mathrm{~S}$.

Pichler, F., \& Wallace, C. (2007). Patterns of formal and informal social capital in Europe. European Sociological Review, 23(4), 423-435.

Pilkington, P. D., Windsor, T. D., \& Crisp, D. A. (2012). Volunteering and subjective well-being in midlife and older adults: The role of supportive social networks. Journals of Gerontology Series B: Psychological Sciences and Social Sciences, 67(2), 249-260.

Pleau, R., \& Shauman, K. (2013). Trends and correlates of post-retirement employment, 1977-2009. Human Relations, 66(1), 113-141.

Principi, A., Galenkamp, H., Papa, R., Socci, M., Suanet, B., Schmidt, A., et al. (2016). Do predictors of volunteering in older age differ by health status? European Journal of Ageing, 13(2), 91-102.

Principi, A., Santini, S., Socci, M., Smeaton, D., Cahill, K. E., Vegeris, S., et al. (2018). Retirement plans and active ageing: Perspectives in three countries. Ageing \& Society, 38(1), 56-82.

Putnam, R. D. (2000). Bowling alone: The collapse and revival of American community. New York: Simon and Schuster. 
Quirke, E., König, H.-H., \& Hajek, A. (2019). Association between caring for grandchildren and feelings of loneliness, social isolation and social network size: A cross-sectional study of community dwelling adults in Germany. British Medical Journal Open. https://doi.org/10.1136/bmjopen-2019-029605.

Robinson, J. P., \& Godbey, G. (2010). Time for life: The surprising ways Americans use their time. University Park: Penn State Press.

Saraceno, C., \& Keck, W. (2010). Can we identify intergenerational policy regimes in Europe? European Societies, 12(5), 675-696.

Schils, T. (2008). Early retirement in Germany, the Netherlands, and the United Kingdom: A longitudinal analysis of individual factors and institutional regimes. European Sociological Review, 24(3), 315-329.

Serrat, R., Scharf, T., Villar, F., \& Gómez, C. (2020). Fifty-five years of research into older people's civic participation: Recent trends, future directions. The Gerontologist, 60(1), e38-e51.

Son, J., \& Wilson, J. (2012). Volunteer work and hedonic, eudemonic, and social well-being. In Sociological Forum, 2012 (Vol. 27(3), pp. 658-681), Wiley Online Library

Strauss, S., \& Trommer, K. (2018). Productive ageing regimes in Europe: Welfare state typologies explaining elderly Europeans' participation in paid and unpaid work. Journal of Population Ageing, 11(4), 311-328.

Tabassum, F., Mohan, J., \& Smith, P. (2016). Association of volunteering with mental well-being: A lifecourse analysis of a national population-based longitudinal study in the UK. British Medical Journal Open, 6(8), e011327.

Ten Bruggencate, T., Luijkx, K. G., \& Sturm, J. (2018). Social needs of older people: A systematic literature review. Ageing \& Society, 38(9), 1745-1770.

van Tilburg, T., Komp, K., \& van Groenou, M. B. (2010). Paid work between age 60 and 70 years in Europe: A matter of socio-economic status? International Journal of Ageing and Later Life, 5(1), 45-75.

Wilson, J. (2000). Volunteering. Annual Review of Sociology, 26(1), 215-240.

World Health Organization. (1948). Constitution of the World Health Organisation. Geneva: WHO.

World Health Organization. (2015). World report on ageing and health. Geneva: WHO.

Zaidi, A., Gasior, K., Zolyomi, E., Schmidt, A., Rodrigues, R., \& Marin, B. (2017). Measuring active and healthy ageing in Europe. Journal of European Social Policy, 27(2), 138-157.

Zuzanek, J., \& Box, S. J. (1988). Life course and the daily lives of older adults in Canada. In K. Altergott (Ed.), Daily life in later life: Comparative perspectives (pp. 147-185). London: Sage Publications.

Publisher's Note Springer Nature remains neutral with regard to jurisdictional claims in published maps and institutional affiliations. 


\section{University Library}

\section{- M M N E R VA A gateway to Melbourne's research publications}

Minerva Access is the Institutional Repository of The University of Melbourne

Author/s:

van Tienoven, TP;Craig, L;Glorieux, I;Minnen, J

Title:

Active Participation and Well-Being Among the Elderly in Belgium and the USA: A CrossNational Time-Use Perspective

Date:

2020-05-28

Citation:

van Tienoven, T. P., Craig, L., Glorieux, I. \& Minnen, J. (2020). Active Participation and WellBeing Among the Elderly in Belgium and the USA: A Cross-National Time-Use Perspective. Social Indicators Research: an international and interdisciplinary journal for quality-of-life measurement, 160 (2-3), https://doi.org/10.1007/s11205-020-02383-y.

Persistent Link:

http://hdl.handle.net/11343/252274 